\title{
MARKERS OF AXIOLOGICAL ESTIMATION IN THE COSSACK PROVERBS AND SAYINGS
}

\author{
Evgeniya A. Murashova \\ Taganrog State Institute named after A.P. Chekhov (Branch of Rostov State University of Economics), \\ Taganrog, Russian Federation
}

\begin{abstract}
The analysis of markers of axiological estimation from positions of modern pragmatics is presented in the article. The author specifies markers of axiological estimation as carriers of a certain type of pragmatic value which vividly reflects axiological references via value estimation of the speaker directed towards the world segment of reality. Some difficulties of the analysis that are caused by the unique features and specific character of the phenomenon under study are explicated, they include: ambivalence of value of axiological pragmatic markers, junction (close coordination) of the subject axiological value and other non-axiological characteristics of a segment of reality represented in Cossack proverbs and sayings, wide range of variations in the way axiological assessment is presented verbally, some ways of the troubles overcoming for a researcher are offered. On the material of the Cossack proverbs and sayings the author estimates classification of markers of axiological assessment with regard to multilayer structure, open and additive character their pragmatic meanings. The usage of lingua-pragmatic experiment resulted in distinguishing reactions of four respondent groups, they mirror semantic associations between metaphysic phenomena and axiological intentions of the speaker: sacred, ethical, utilitarian (practical), vital, aesthetic, intellectual, hedonistic, and general-estimation markers (their enumeration corresponds to decrease in the value estimation).

Key words: linguistic pragmatics, pragmatical value, axiology, markers of axiological assessment, Cossack discourse.

Citation. Murashova E.A. Markers of Axiological Estimation in the Cossack Proverbs and Sayings. Vestnik Volgogradskogo gosudarstvennogo universiteta. Seriya 2, Yazykoznanie [Science Journal of Volgograd State University. Linguistics], 2017, vol. 16, no. 2, pp. 127-134. (in Russian). DOI: https://doi.org/10.15688/jvolsu2.2017.2.13.

УДК $811.161 .1 ’ 42: 398.9$

Дата поступления статьи: 03.02.2017

ББК $81.411 .2-51$

Дата принятия статьи: 20.03.2017
\end{abstract}

\section{МАРКЕРЫ АКСИОЛОГИЧЕСКОГО ОЦЕНИВАНИЯ В КАЗАЧЬИХ ПОСЛОВИЦАХ И ПОГОВОРКАХ}

\author{
Евгения Анатольевна Мурашова \\ Таганрогский институт им. А.П. Чехова (филиал) Ростовского государственного \\ экономического университета, г. Таганрог, Российская Федерация
}

\begin{abstract}
Аннотация. В статье представлен анализ маркеров аксиологического оценивания с позиций современной лингвистической прагматики; уточнено определение маркеров аксиологического оценивания как носителей того или иного типа прагматического значения, который соответствует экспликации аксиологических референций, представляющих ценностное отношение отправителя к отображаемому им фрагменту действительности; обозначены некоторые сопряженные с уникальными свойствами исследуемого феномена сложности анализа, в их числе: амбивалентность значения аксиологических прагматических маркеров, «сращение» выражения субъективного аксиологического отношения и выражения других неаксиологических характеристик изображаемого фрагмента действительности; широкий спектр варьирования вербализации аксиологической оценки и т. д. Намечены основные пути их преодоления. На материале казачьих пословиц и поговорок детализирована классификация маркеров аксиологического оценивания с учетом многослойности, незамкнутости и аддитивности их прагматического значения. В ходе лингвопрагматического экспери(?) мента были получены реакции четырех групп респондентов, отражающие смысловые ассоциации между
\end{abstract}




\section{РАЗВИТИЕ И ФУНКЦИОНИРОВАНИЕ РУССКОГО ЯЗЫКА}

метафизическими явлениями и аксиологическими установками отправителя текста. На основе анализа усредненных реакций были выделены следующие типы маркеров аксиологического оценивания (перечень дан в порядке убывания значимости маркера): священные, этические, утилитарные (практические), витальные, эстетические, интеллектуальные, гедонистические, общеоценочные.

Ключевые слова: лингвистическая прагматика, прагматическое значение, аксиология, аксиологическая оценка, маркер аксиологической оценки, казачий дискурс.

Цитирование. Мурашова Е. А. Маркеры аксиологического оценивания в казачьих пословицах и поговорках // Вестник Волгоградского государственного университета. Серия 2, Языкознание. - 2017. - Т. 16, № 2. - C. 127-134. - DOI: https://doi.org/10.15688/jvolsu2.2017.2.13.

1

Изучение вербализации аксиологического оценивания продиктовано неослабевающим интересом исследователей гетерогенных речевых проявлений к феномену субъектно маркированной интерпретации изображаемых отправителем текста явлений действительности.

Использование методов и приемов современной антропоцентрически ориентированной научной парадигмы для изучения вербализации аксиологического оценивания обусловливает появление большого количества научных трудов, раскрывающих различные аспекты возникновения и функционирования данного феномена. В качестве иллюстрации приведем новейшие из них.

Современные исследования, осуществленные в русле концептуальной лингвистики, постулируют наличие ценностного содержания фактически у любого слова, помещенного в соответствующий контекст (см., например [Чекулай, Прохорова, 2016, с. 44-45]). Речевая экспликация ценностного осмысления деятельности, в том числе деятельности, направленной на совмещение внеязыковых процессов и вербализующих их знаков, анализируется на примере метафорических моделей описания ситуаций оценки (моделей ценностного осмысления действительности) (например: [Чекулай, Прохорова, 2016]).

Аксиологические маркеры изучаются представителями концептуального анализа на материале различных типов дискурсов, в частности образовательного, как носители аксиологических смыслов, которые могут быть применимы по отношению к наделяемым определенной значимостью и характеризуемым личностью в процессе общения ценностям: предметам, явлениям, качествам и т. д. [Артюхова, 2016].
В рамках когнитивной лингвистики рассматривается аксиологический потенциал бинарных оппозиций, вербализующих представления человека относительно значимости определенных признаков для оценочной деятельности отдельного индивида или целого языкового коллектива. Особое внимание в таких работах уделяется анализу вербализующих бинарные оценочные оппозиции единиц языка, и в частности оценочного семантического компонента значения слов, являющихся объективаторами данных оппозиций, компонента, реализуемого посредством смысловых маркеров «хорошо / плохо» [Григорьева, 2016, с. 173].

С позиций современной семантики и истории языка изучаются выражающие оценку функционально-семантические единицы, а именно эвалюативные словесные ряды (описание, повествование, толкование) как законченные смысловые отрезки, организующие текст, например, на материале древнерусских текстов (см.: [Пименова, 2016]). Оценка трактуется при этом как выражение субъективного отношения к определенной ценности, основанное на ментальных стереотипах человека [Пименова, 2016, с. 18].

С позиций ряда актуальных исследований, объединяющих в себе признаки различных научных направлений, например формальной аксиологии, теории речевых актов и прагмалингвистики, аксиологические маркеры рассматриваются в рамках оценочных высказываний как средства вербализации отношения человека к различным аспектам окружающей его действительности [Старостина, 2007 , с. 232]. При этом особо подчеркивается когнитивная значимость реализуемой средствами языка оценки, представляющей результаты познавательного опыта человека и социальной группы, в которую он входит [Старостина, 2007, с. 233], универсальность оцен- 
ки, восходящей к различным функциям языка [Старостина, 2007, с. 234], а также широкий диапазон лингвистического варьирования оценки, вербализующейся с помощью различных средств языка в рамках отдельных оценочных суждений [Старостина, 2007, с. 237].

Наиболее продуктивным на фоне означенных и других исследований (см. подробнее [Мурашова, 2015, с. 147-160]) представляется лингвопрагматический подход.

\section{2}

В рамках лингвистической прагматики аксиологические маркеры (маркеры аксиологического оценивания) трактуются как носители определенного типа прагматического значения, соответствующие экспликации аксиологических референций, которые вербализуют ценностное отношение отправителя к отображаемому им фрагменту действительности [Мурашова, 2015, с. 151].

Ценностное отношение отправителя к отображаемому им фрагменту действительности может выражаться на уровне семантики с помощью субъективно-оценочных лексических единиц, а также с помощью речевых средств, выражающих оценку посредством морфологической (например, степени сравнения прилагательных), словообразовательной (например, суффиксы субъективной оценки) или синтаксической формы (например, субъективно-оценочные вводные конструкции, сравнения) (см.: [Мурашова, 2015, с. 154]).

В ходеряда проведенных нами лингвопрагматических экспериментов особенности маркеров аксиологического оценивания были проанализированы с учетом усредненных реакций респондентов, носителей различных индивидуальных и социальных характеристик. Респонденты (всего 190 человек, объединенные в группы соответственно их возрасту, родному языку и гендерной принадлежности: первая группа мужчины в возрасте от 17 до 25 лет, носители русского языка; вторая группа - женщины в возрасте от 17 до 25 лет, носители русского языка; третья группа - мужчины в возрасте от 26 до 47 лет, носители русского языка; четвертая группа - женщины в возрасте от 26 до 47 лет, носители русского языка) изучили розданные им тексты-образцы, выделив ре- чевые единицы, которые, по их мнению, в заданном дискурсивном окружении (текстах казачьего дискурса) представляют ценностное отношение отправителя к отображаемому им фрагменту действительности. Далее выделенные респондентами маркеры были систематизированы соответственно языковым уровням и проанализированы на предмет выявления статуса аксиологической оценки (абсолютной или относительной). Кроме того, была уточнена структура высказываний с актуализированными в них аксиологическими маркерами: «S полагает, что $O$ есть $M »$, где $S$ - субъект, $O$ - объект, $M$ - модальное понятие (аксиологический модальный оператор) (см. подробно [Мурашова, 2015, с. 147-160]). Отдельным результатом работы с текстами казачьего дискурса стала выборка казачьих пословиц и поговорок (всего 445 единиц), в которых были зафиксированы маркеры аксиологического оценивания (340 маркеров).

Обращение к методам и приемам лингвистической прагматики позволило провести анализ актуализации аксиологических маркеров, преодолев ряд сложностей (некоторые из них кратко обозначим далее).

Во-первых, эксплицируя ценностное отношение отправителя к отображаемому им фрагменту действительности (аксиологическую оценку) путем актуализации аксиологических маркеров в условиях конкретной коммуникативной ситуации, субъект-отправитель, с одной стороны, реализует индивидуальные интенции, пресуппозиции и особенности собственного речевого поведения, с другой стороны, он реализует конвенционально закрепленные стереотипы интенций, пресуппозиций и речевого поведения носителей заданного языка или диалекта.

Во-вторых, сложность анализа речевых средств-маркеров вербализации аксиологической референции (оценки) увеличивается за счет «сращения» выражения собственно некого субъективного ценностного (аксиологического) отношения и выражения других неаксиологических характеристик изображаемого фрагмента действительности, в том числе эмоционально оценочных. С этим связана амбивалентность (двойственность, противоречивость) значения аксиологических прагматических маркеров. 


\section{РАЗВИТИЕ И ФУНКЦИОНИРОВАНИЕ РУССКОГО ЯЗЫКА}

В-третьих, вербализация аксиологической оценки (референции) имеет широкий спектр варьирования, поскольку может быть представлена средствами различных уровней языка и их сочетаниями, интерпретация которых зависит также от индивидуально и конвенционально обусловленных особенностей интенций, пресуппозиций и речевого поведения получателя.

Кроме того, с помощью разноуровневых средств языка может вербализоваться оценка - от ярко выраженной до едва различимой (и потому трудно фиксируемой и интерпретируемой вне условий контекста).

\section{3}

Данные феномены усложняют выведение сколько-нибудь строгой классификации аксиологических маркеров, хотя и не нивелируют значения классификаций, предлагаемых представителями различных научных направлений. Например, с позиций концептуальной лингвистики И.С. Артюхова выделяет шесть групп аксиологических маркеров соответственно характеризуемым личностью ценностям: 1) человек, 2) государство, 3) духовные и нравственные качества, 4) культура, искусство и литература, 5) наука и знания, 6) труд [Артюхова, 2016].

В рамках аксиологической фразеологии Л.К. Байрамова предложила классификацию аксиологем в соответствии со следующими конвенциональными ценностями / антиценностями: витальными (жизнь - смерть; здоровье - болезнь), гедонистическими (счастье несчастье), священными (родина - чужбина), социально-утилитарными (труд - безработица / лень / отдых), материально-утилитарными (богатый - бедный), интеллектуально-познавательными (ум - глупость), нравственноэтическими (правда - ложь), эмоциональноутилитарными (смех - плач), религиозными (рай - ад) [Байрамова, 2014, с. 10; Байрамова, 2015, с. 343-347].

Классификация маркеров - носителей аксиологического значения может строиться и с учетом первичности / вторичности оценки в их семантике. К маркерам, содержащим оценку в первичной семантике, относятся те, которые реализуются в оценочных оппозици- ях, специально созданных для выражения оценки (неметафорических). К маркерам, содержащим основанную на метафорическом переносе вторичную оценку, причисляются те, которые реализуются в оценочных оппозициях, отражающих эмпирически воспринимаемые человеком элементы действительности (когнитивно-метафорические) [Григорьева, 2016, с. 174]. Маркеры первой группы - это, например, слова хорошо / плохо, умныии / глуnый, счастье / несчастье, второй группы высокий / низкий, иирокий / узкий, белый / черный [Григорьева, 2016, с. 174].

Вербализованная оценка может разделяться на эмоциональную и рациональную в зависимости от преобладающего в ней субъективного (эмоционального) или объективного (рационального) начала [Старостина, 2007 , c. 236].

Наличие большого количества классификаций свидетельствует о многослойности, незамкнутости и аддитивности прагматического значения аксиологических маркеров, что необходимо учитывать в ходе лингвопрагматического анализа речевых единиц.

\section{4}

С учетом выявленной сложности прагматического значения речевых единиц и их анализа, а также разнообразия классификаций аксиологических маркеров, рассмотрим казачьи пословицы и поговороки с целью уточнить классификацию маркеров, содержащих аксиологическое оценивание. Определяя аксиологические маркеры как носители прагматического значения, соответствующего экспликации аксиологических референций, с учетом смысловых ассоциаций между метафизическими явлениями и аксиологическими установками отправителя на предыдущих этапах исследования, мы выделили общие (общеоценочные), интеллектуальные, эстетические, этические и практические аксиологические оценочные маркеры [Мурашова, 2015, с. 151].

Лингвопрагматическое исследование аксиологических маркеров с привлечением реакций четырех групп респондентов на материале казачьих пословиц и поговорок позволило провести более подробную градацию указанных групп маркеров и переструктури- 
E.A. Мурашова. Маркеры аксиологического оценивания в казачьих пословицах и поговорках

ровать данные группы согласно смысловым ассоциациям между метафизическими явлениями и аксиологическими установками отправителя, отмеченными респондентами. Полученные данные были систематизированы и зафиксированы в табличной форме (см. таблицу, в которой количество маркеров указано в абсолютном выражении и процентном отношении к общему количеству пословиц и поговорок, входящих в выборку).

Согласно таблице иерархия актуализации аксиологических оценочных маркеров может быть представлена следующим образом (в порядке убывания значимости).

I. Священные аксиологические маркеры $(32,94 \%)$ :

- вера - неверие (Богу молись, но ик берегу гребись / душу - Богу, сердие - людям, жизнь - Отечеству, честь - никому / конь под нами, а Бог над нами / слава тебе, Господи, что мы казаки / Бог - не Микиика, у него своя книжка);

- дом (добыть - или дома не быль / отичь для детей дом строили);

- родина - чужбина (казак скорее умрет, чем с родной земли сойдет / душу -
Богу, сердие - людям, жизнь - Отечеству, честь - никому / да спасет нас родная земля / иельмм бы остаться, да с Доном не расстаться);

- семья (казак без жены что шашка без ножен / казак на коня садится, а его невеста родится / дед был казак, отец сын казачий, а тыл - хвост собачий / казацкому роду нема переводу / нет такого друж$\kappa a$, как родная матуика / родительское благословление и в воде не тонет, и в огне не горит).

II. Этические аксиологические маркеры $(18,83 \%)$ :

- дружба - вражда (конь познается $в$ езде, а друг в беде / конь да ночь - казаковы товарищи / кто от товарища отстанет, нехай от того икура отстанет);

- правда - ложь (брехня не лежит у плетня / где Дон, там и правда / не бреши жене на базу, а коню в дороге / по правде и сила);

- храбрость, смелость (казак смерти не боится - он Богу нашему знадобится / казачья смелость порушит любую крепость / кто пули боится - тот в казаки не годит-

Актуализация аксиологических оценочных маркеров

в казачьих пословицах и поговорках

\begin{tabular}{|c|c|c|}
\hline \multicolumn{3}{|c|}{ Аксиологические оценочные маркеры } \\
\hline Общеоценочные (хорошо - плохо) & 14 & $14(4,12 \%)$ \\
\hline \multicolumn{3}{|l|}{ Священные } \\
\hline вера - неверие & 30 & \multirow{4}{*}{$112(32,94 \%)$} \\
\hline дом & 11 & \\
\hline родина - чужбина & 30 & \\
\hline семья & 41 & \\
\hline \multicolumn{3}{|l|}{ Этические } \\
\hline дружба - вражда & 8 & \multirow{3}{*}{$64(18,83 \%)$} \\
\hline правда - ложь & 26 & \\
\hline храбрость, смелость & 30 & \\
\hline \multicolumn{3}{|l|}{ Утилитарные (практические) } \\
\hline труд - безработица & 14 & \multirow{3}{*}{$47(13,82 \%)$} \\
\hline отдых - лень & 7 & \\
\hline богатство - бедность & 26 & \\
\hline \multicolumn{3}{|l|}{ Витальные } \\
\hline жизнь - смерть & 7 & \multirow{2}{*}{$39(11,47 \%)$} \\
\hline здоровье - болезнь & 32 & \\
\hline Эстетические (красота - безобразность) & 30 & $30(8,82 \%)$ \\
\hline Интеллектуальные (ум - глупость) & 19 & $19(5,59 \%)$ \\
\hline \multicolumn{3}{|l|}{ Гедонистические } \\
\hline счастье - несчастье & 8 & \multirow{3}{*}{$15(4,41 \%)$} \\
\hline удача - неудача & 1 & \\
\hline слава - безвестность & 6 & \\
\hline & Итого & $340(100 \%)$ \\
\hline
\end{tabular}




\section{РАЗВИТИЕ И ФУНКЦИОНИРОВАНИЕ РУССКОГО ЯЗЫКА}

ся / с каждым боем казак храбрее, с каждым бегом конь резвее).

III. Утилитарные (практические) аксиологические маркеры $(13,82$ \%):

- труд - безработица (без работы, как без заботы, и умный казак в дураках ходит / донская земля дармоедов не кормит / ни одной работе не след зря пропадать / от безделья не бывает у казака веселья);

- отдых - лень (весель привалы, где казаки запеваль / ой, печь моя, печь! коли б я на тебя, а тыл на коня, славный казак был бы из меня!);

- богатство - бедность (казак хороший, та нема грошей / богач, продай куски или продай лохони / ни конь без узды, ни богатство без ума / у победы богатый обоз).

IV. Витальные аксиологические маркеры $(11,47 \%)$ :

- жизнь - смерть (были б жнивы, а голь будем / казак жнивет не тем, что есть, а тем, что будет / что казаку здорово, то немиу смерть);

- здоровье - болезнь (как ни на бабушке дрисьня, так она б за море ушла / кому булава в руки, а кому - костыль / сопливое, но свое / схватило кота поперек живота).

V. Эстетические аксиологические маркеры $(8,82 \%)$ : добрый конь в беге, что сокол в небе / казак донской, что карась озерной: икрян, прян и солен / кони в лугах, что жемчуг в шелках.

VI. Интеллектуальные аксиологические маркеры $(5,59 \%)$ без работы, как без заботы, и умный казак в дураках ходит / зипуны у нас серые, а умы-то бархатныя / казак молчит, а все знает / кто присказки знает, тот в жизни много понимает / отчего ты так глуп? - у нас вода такая.

VII. Гедонистические аксиологические маркеры $(4,41 \%)$ :

- счастье - несчастье (Бог не без милости, казак не без счастья);

- удача - неудача (на удачу казак на коня садится, на удачу его и конь бьет);

- слава - безвестность (в бою казак себя славит не языком, а конем да клинком / где казак, там и слава / житье собачье, зато слава казачья / слава казацкая никогда не сгинет).
VIII. Общеоценочные аксиологические маркеры (4,12 \%): атамана из плохого казака не получится / добрый казак бачет, где атаман скачет / добрый казак не брезгует, что попало, то и трескает / казак хороший, та нема грошей / плох конь, коль не скачет, плох казак, коли плачет.

Выделенные нами группы не являются замкнутыми, поскольку, будучи помещенными в определенный контекст, одни и те же маркеры могут интерпретироваться по-разному. Например, в пословице за морем теплее, а дома казаку светлее лексический маркер дом потенциально может интерпретироваться как обозначение Родины, родной стороны и как обозначение дома, где проживает казачья семья. Кроме того, сама классификация может быть в дальнейшем расширена за счет выделения дополнительных метафизических оснований аксиологической оценки.

5

Иерархия в актуализации аксиологических маркеров в целом отражает имманентные признаки казачьего дискурса: регулярную экспликацию священных для казачества ценностей (Семья, Вера, Отечество, Дом), морально-этических (Храбрость, Правда, Дружба) и утилитарных (Труд, Богатство, Отдых) норм. Эти признаки совпадают с доминантными ценностями самобытной южнорусской казачьей культуры.

Проведенное исследование свидетельствует о перспективности лингвопрагматического подхода в изучении вербализации аксиологического оценивания, который позволяет приблизиться к решению важной проблемы современной антропоцентрически ориентированной научной парадигмы - представления субъекта и проецируемого им образа действительности средствами данного субнационального языка (например, казачьего диалекта).

\section{СПИСОК ЛИТЕРАТУРЫ}

Артюхова, И. С. Аксиологические основания концептуального анализа образовательного дискурса / И. С. Артюхова // Universum: психология и образование. - 2016. - № 9 (27). - Электрон. текстовые дан. - Режим доступа: http://7universum.com/ 
ru/psy/archive/item/3551 (дата обращения: 17.11.2016). - Загл. с экрана.

Байрамова, Л. К. Пословицы в аксиологическом фразеологическом словаре русского языка: словаре ценностей и антиценностей / Л. К. Байрамова // Вестник Новгородского государственного университета им. Ярослава Мудрого. - 2014. № 77. - С. 10-12.

Байрамова, Л. К. Противоречия в аксиологической фразеологии / Л. К. Байрамова // Устойчивые фразы в парадигмах науки : материалы Междунар. науч. конф., посвящ. 100-летию со дня рождения Владимира Леонидовича Архангельского. Омск : С-Принт, 2015. - С. 343-348.

Григорьева, Т. В. Аксиологические возможности оппозиции (опыт когнитивно-аксиологического моделирования) / Т. В. Григорьева // Исследования по семантике : межвуз. науч. сб. с междунар. участием. - Уфа: РИЦБашГУ, 2016. - Вып. 26. - С. 172-176.

Мурашова, Е. А. Прагматическое значение речевой единицы. Проблемы и перспективы / Е. А. Мурашова. - М. : Перо, 2015.-292 с.

Пименова, М. В. Способы организации древнерусского текста и выражение оценки / М. В. Пименова // Вестник Волгоградского государственного университета. Серия 2, Языкознание. - 2016. T. 15, № 2. - C. 17-24. - DOI: http://dx.doi.org/ 10.15688/jvolsu2.2016.2.2.

Старостина, Ю. С. Интерпретация логической оценки в терминах аксиологических суждений / Ю. С. Старостина // Вестник Самарского государственного университета. - 2007. - № 3 (53). - С. 232-241.

Чекулай, И. В. Ценностно-деятельностные метафорические модели в создании системы ценностных концептов английского языка / И. В. Чекулай, О. Н. Прохорова // Научный результат. Серия «Вопросы теоретической и прикладной лингвистики». - 2016. - Т. 2, № 1 (7). - С. 44- 47.

\section{REFERENCES}

Artyukhova I.S. Aksiologicheskie osnovaniya kontseptualnogo analiza obrazovatelnogo diskursa [Axiological Bases of the Conceptual Analysis of the Educational Discourse]. Universum: psikhologiya $i$ obrazovanie [Universum: Psychology and Education], 2016, no. 9 (27). URL: http://7universum.com/ru/psy/ archive/item/3551. (accessed November 17, 2016).

Bayramova L.K. Poslovitsy v aksiologicheskom frazeologicheskom slovare russkogo yazyka: slovare tsennostey $\mathrm{i}$ antitsennostey [Proverbs in the Axiological Phraseological Dictionary of the Russian Language Dictionary of Values and Anti-Values]. Vestnik Novgorodskogo gosudarstvennogo universiteta im. Yaroslava Mudrogo, 2014, no. 77, pp. 10-12.

Bayramova L.K. Protivorechiya v aksiologicheskoy frazeologii [Contradictions in Axiological Phraseology]. Ustoychivye frazy $v$ paradigmakh nauki: materialy Mezhdunar. nauch. konf., posvyashch. 100-letiyu so dnya rozhdeniya Vladimira Leonidovicha Arkhangelskogo [Set Phrases in Academic Paradigms. Materials of the International Scientific Conference Devoted to the $100^{\text {th }}$ Birth Anniversary of Vladimir L. Arkhangelsky]. Omsk, SPrint Publ., 2015, pp. 343-348.

Grigoryeva T.V. Aksiologicheskie vozmozhnosti oppozitsii (opyt kognitivno-aksiologicheskogo modelirovaniya) [Axiological Opportunities of Opposition (Experience of Cognitive and Axiological Modeling)]. Issledovaniya po semantike: mezhvuz. nauch. sb. s mezhdunar. uchastiem [Research on Semantics. The Interuniversity Scientific Collection with the International Participation]. Ufa, RIC BashGU Publ., 2016, iss. 26, pp. 172-176.

Murashova E.A. Pragmaticheskoe znachenie rechevoy edinitsy. Problemy $i$ perspektivy [Pragmatical Value of Speech Unit. Problems and Prospects]. Moscow, Pero Publ., 2015. 292 p.

Pimenova M.V. Sposoby organizatsii drevnerusskogo teksta i vyrazhenie otsenki [Ways of the Old Russian Text Organization and Expression of Assessment]. Vestnik Volgogradskogo gosudarstvennogo universiteta. Seriya 2, Yazykoznanie [Science Journal of Volgograd State University. Linguistics], 2016, vol. 15, no 2, pp. 17-24. DOI: http://dx.doi.org/10.15688/ jvolsu2.2016.2.2.

Starostina Yu.S. Interpretatsiya logicheskoy otsenki $\mathrm{v}$ terminakh aksiologicheskikh suzhdeniy [Interpretation of Logical Assessment in Terms of Axiological Judgments]. Vestnik Samarskogo gosudarstvennogo universiteta, 2007, no. 3 (53), pp. 232-241.

Chekulay I.V., Prokhorova, O.N. Tsennostnodeyatelnostnye metaforicheskie modeli v sozdanii sistemy tsennostnykh kontseptov angliyskogo yazyka [Valuable and Activity Metaphorical Models in Creation of System of Valuable Concepts of English]. Nauchnyy rezultat. Seriya «Voprosy teoreticheskoy i prikladnoy lingvistiki», 2016, vol. 2, no. 1 (7), pp. 44-47. 


\section{РАЗВИТИЕ И ФУНКЦИОНИРОВАНИЕ РУССКОГО ЯЗЫКА}

\section{Information About the Author}

Evgeniya A. Murashova, Candidate of Sciences (Philology), Associate Professor, German and French Languages Department, Taganrog State Institute named after A.P. Chekhov (Branch of Rostov State University of Economics), Petrovskaya St., 68, 347900 Taganrog, Russian Federation, shenetschka@rambler.ru, http://orcid.org/0000-0002-6018-955X.

\section{Информация об авторе}

Евгения Анатольевна Мурашова, кандидат филологических наук, доцент кафедры немецкого и французского языков, Таганрогский институт им. А.П. Чехова (филиал) Ростовского государственного экономического университета, ул. Петровская, 68, 347900 г. Таганрог, Российская Федерация, shenetschka@rambler.ru, http://orcid.org/0000-0002-6018-955X. 